\title{
Atuação sistêmica do médico de família: uma visão segundo o modelo bioecológico do desenvolvimento humano
}

\author{
Systemic performance of the family physician: a view according to the \\ bioecological model of human development
}

Karina de Paula Bastos Santos', Elisângela Böing ${ }^{2}$

DOI: 10.1590/0103-1104201912125

RESUMO A medicina de família e comunidade é responsável pela assistência da maior parte dos problemas de saúde de uma população, gerenciando o cuidado das pessoas. A perspectiva sistêmica preconiza que os acontecimentos relacionados com os indivíduos resultam das interações estabelecidas com outras pessoas e contextos. Este relato traz reflexões e sugestões de aprimoramento sobre o trabalho de uma médica de família e comunidade como terapeuta de família na atenção primária. O método utilizado consistiu na descrição da atuação da médica de acordo com o modelo bioecológico do desenvolvimento humano. Percebeu-se que a formação em terapia relacional sistêmica pode potencializar as habilidades e resolutividade do médico de família.

PALAVRAS-CHAVE Terapia familiar. Atenção Primária à Saúde. Medicina de família e comunidade.

ABSTRACT Family practice is the specialty that solves most of the health problems of a given community, by managing people's health care needs. According to the systemic relational therapy, what happens to an individual is a result from interactions with other people. The present experience report reviews issues and brings suggestions of improvement on the work of a family physician and therapist's practice in a primary care setting. The method was based on a description of the physician's work according to the bioecological model of human development. Results showed that systemic relational therapy can improve the family physician's skills to solve health problems.

KEYWORDS Family therapy. Primary Health Care. Family practice.

\footnotetext{
1 Prefeitura de São 


\section{Introdução}

A Atenção Primária à Saúde é um ponto da rede de atenção que funciona como porta de entrada para $o$ atendimento das necessidades de um indivíduo e de uma comunidade em um sistema de saúde' $\mathbf{1}$ Quando utilizada como estratégia para organizar um sistema de saúde, tem potencial para resolver a maior parte dos problemas de saúde de uma população ${ }^{2}$.

No Brasil, como a Constituição Federal de 1988 define a saúde como o direito de todos e dever do estado, o sistema de saúde é organizado por meio do Sistema Único de Saúde. A principal política adotada na atenção primária é a Estratégia Saúde da Família (ESF) ${ }^{3}$. Os profissionais que nela trabalham deveriam conhecer o território e a população pela qual eles são responsáveis; realizar um cuidado longitudinal e fazer vínculo com os usuários e as famílias. Quando conseguem cumprir com essas funções, podem resolver a maior parte dos problemas de saúde do território, tornando os serviços de saúde acessíveis à população.

Essas diretrizes específicas da ESF relacionam-se diretamente com os princípios da atenção primária: primeiro contato, longitudinalidade, integralidade e coordenação do cuidado como atributos essenciais, e atenção à saúde centrada na família, orientação comunitária e competência cultural como atributos derivados. Tais diretrizes funcionam como bússola - para guiar o trabalho nesse nível de atenção'.

A equipe da ESF precisa manejar usuários com multimorbidades, sintomas indiferenciados, pelo fato de estarem no início de uma doença, por exemplo, ou por não se encaixarem em um diagnóstico definitivo. Além disso, deve ser uma equipe atenta aos vários fatores do processo saúde-doença e às relações entre o contexto social, familiar, econômico, entre outros, no processo de adoecimento.

O médico de família e comunidade é o especialista com uma formação específica para atuar na atenção primária. De acordo com McWhinney e Freeman ${ }^{4}$, esse profissional está disponível para lidar com qualquer problema de saúde que as pessoas sob sua responsabilidade apresentarem, mesmo que o indivíduo precise ser encaminhado para um outro nível de atenção. Ele estabelece uma relação com as pessoas antes mesmo de os problemas de saúde aparecerem.

Essa estruturação do cuidado faz com que a atuação desses profissionais se distancie de uma visão linear, ou seja, de uma ótica científica moderna de causa e efeito. Eles trabalham diretamente com os pressupostos epistemológicos pós-modernos que regem o pensamento sistêmico - a complexidade, instabilidade e intersubjetividade - para compreender o processo saúde-doença $a^{5}$. Entretanto, além de compreender, é preciso intervir sobre esses aspectos.

Segundo Doherty e Baird, citado por McWhinney e Freeman ${ }^{4}$, existem cinco níveis de envolvimento da equipe de saúde com a família do usuário:

- grau 1: pouco envolvimento, por exemplo, avisar sobre a morte de uma pessoa;

- grau 2: existe um fluxo de informações e orientações. Há uma conversa sobre os tipos de intervenções diagnósticas e tratamento, o profissional está aberto a responder às dúvidas e inquietações que a família possa ter sobre o quadro clínico;

- grau 3: aprofundamento do grau 2, uma vez que o profissional entende sobre teorias do desenvolvimento da família e suas reações a situações/eventos estressantes;

- grau 4: o profissional atua sob uma perspectiva sistêmica para entender melhor o contexto da família e fazer intervenções adequadas para o momento, sendo também capaz de conduzir reuniões de família;

- grau 5: o profissional realiza a terapia familiar, fazendo intervenções que conduzem as famílias a gerirem melhor seus 
problemas, levando-as a uma nova forma de funcionamento.

De acordo com o currículo baseado em competências para medicina de família e comunidade, o grau 5 é uma competência avançada de um médico de família, o que exige uma formação específica ${ }^{6}$. A formação em terapia relacional sistêmica traz subsídios teóricos e metodológicos para uma intervenção contextualizada que a atenção primária requer. Entretanto, são poucos os relatos na literatura sobre médicos de família que realizem intervenções sistêmicas ${ }^{\mathbf{7}, \mathbf{8}}$.

Destarte, o objetivo deste artigo consiste em trazer reflexões sobre o trabalho do médico de família e comunidade com famílias segundo a perspectiva sistêmica. Serão relacionados alguns conceitos-chave e teorias sistêmicas ao trabalho do médico de família, avaliando o quanto a prática relatada consegue assumir, de fato, uma perspectiva sistêmica. Propostas de intervenção com o objetivo de melhorar a atuação do médico, enquanto terapeuta, serão sugeridas.

\section{Modelo Processo-Pessoa- Contexto-Tempo (PPCT)}

O modelo bioecológico do desenvolvimento humano, também conhecido como Modelo PPCT, foi desenvolvido pelo psicólogo Urie Bronfenbrenner. Pressupõe que o desenvolvimento humano é o resultado de interações que acontecem em quatro grandes áreas: processos proximais (relações que promovem desenvolvimento), os atributos da pessoa, o contexto em que ela está inserida e o tempo9 (figura 1). Os processos proximais englobam a dinâmica de relação entre a pessoa e o seu contexto.

Figura 1. Modelo Processo-Pessoa-Contexto-Tempo

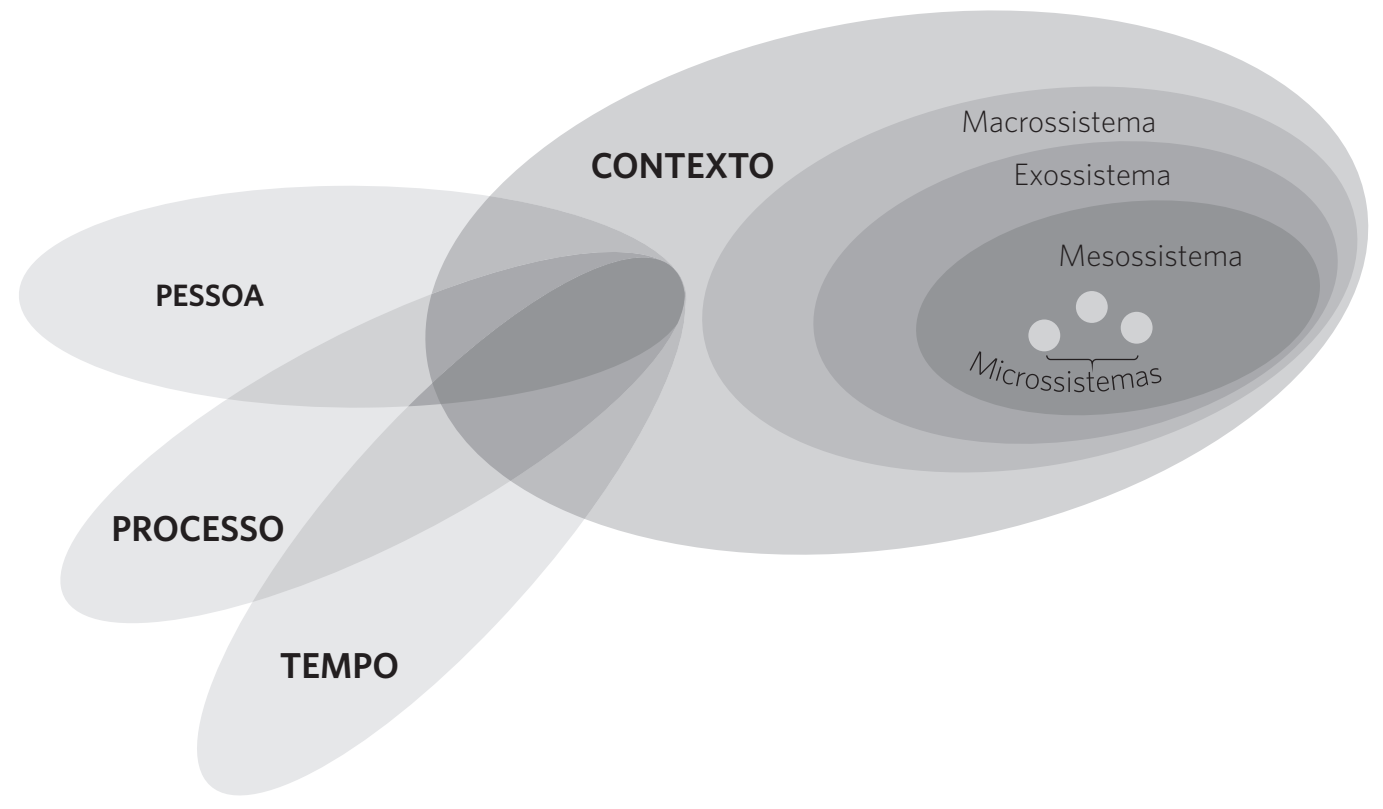


As características da pessoa englobam a individualidade ${ }^{10}$. Características genéticas podem influenciar o comportamento da pessoa e sua suscetibilidade a diversas situações do ambiente.

Em relação ao contexto, Bronfenbrenner ${ }^{10}$ descreve os diversos contextos em níveis ecológicos, que se encaixam de forma progressiva:

- microssistema: representa o ambiente mais imediato que a pessoa frequenta. Os microssistemas determinam padrões de interação da pessoa, estimulando-a ou inibindo-a em diversos tipos de relações interpessoais. No caso de uma criança, por exemplo, seus microssistemas podem ser sua família, a escola.

- mesossistema: é a interação entre os microssistemas da pessoa. No exemplo da criança, o microssistema família interfere no microssistema escola, e vice-versa.

- exossistema: é um ambiente em que a pessoa não está inserida, mas que afeta indiretamente o seu desenvolvimento. No caso de uma criança que mora com os pais, o trabalho de cada um deles, o grupo de amigos dos pais, representam para a criança exossistemas.

- macrossistema: corresponde a aspectos mais globais. A cultura da comunidade em que a pessoa está inserida, situação política etc. Esse nível exerce influência sobre todos os demais.

A quarta área é o tempo ou cronossistema. Ele engloba três dimensões: envelhecimento da pessoa, o tempo do ciclo de vida familiar e o tempo histórico, que trata das questões mais globais do tempo.

\section{Métodos}

Este artigo é um relato de experiência do trabalho realizado por uma das autoras, que é médica de família e comunidade e fez a formação em terapia relacional sistêmica. A médica trabalhava em um centro de saúde que faz parte da atenção primária de um município do sul do Brasil. Descreveu-se a atuação sistêmica dessa profissional utilizando o modelo bioecológico de Bronfenbrenner. Foram analisadas as características da pessoa/médico de família, os processos proximais envolvidos no desenvolvimento do trabalho médico e sistêmico, bem como os variados contextos nos quais a médica estava inserida e o tempo.

Por ser um relato de experiência de uma das autoras, a descrição e a discussão dos fatores relacionados com pessoa, processo, contexto e tempo foram relatados na primeira pessoa do singular. Isso traz a este relato o aspecto da intersubjetividade presente na perspectiva sistêmica, uma vez que, dessa forma, é possível que o profissional reflita sobre sua subjetividade e a relação desta com o seu fazer e seu contexto.

Entre os processos proximais, foram exploradas as interações com os usuários, e recortes de casos/situações ilustraram a discussão das intervenções realizadas. Além disso, foram levantadas propostas de atuação sistêmica de acordo com alguns modelos da terapia de família.

\section{Resultados e discussão}

\section{Pessoa}

A prática do médico de família é orientada por alguns fundamentos cujo intuito consiste em realizar um manejo adequado dos problemas de saúde. Como médica de família e comunidade, fui treinada para fazer abordagem individual e atender aos problemas clínicos mais prevalentes do território. Para alcançar esse objetivo, precisava associar três ferramentas essenciais para o trabalho do médico de família: habilidades de comunicação, o raciocínio clínico adequado para esse nível de atenção à saúde e a medicina baseada em evidências ${ }^{6}$.

$\mathrm{Na}$ abordagem individual, havia demandas diversificadas, por exemplo, sintomas 
indiferenciados, problemas agudos, doenças crônicas, agravos de saúde relacionados com o contexto social, comunitário e familiar, entre outros. Foi possível observar uma situação comum nas unidades de atenção primária, que é a elevada utilização dos serviços de saúde por parte de alguns usuários. Quando isso acontece, se a equipe de saúde e o médico não possuem o preparo adequado para o manejo desses casos, podem rotular essas pessoas como 'chatas', 'poliqueixosas', sem reconhecer as demandas que as levam às Unidades Básicas de Saúde. Por isso, não é suficiente apenas diagnosticar e tratar as doenças. É preciso ter uma compreensão ampla sobre os influentes do estado de saúde e do processo saúde-doença.

Minhas habilidades para condução das consultas melhoraram usando os preceitos da pragmática da comunicação humana a partir do modelo comunicacional"1". Consegui ampliar o olhar sobre as formas de comunicação não verbal durante as consultas, perceber os paradoxos da comunicação e trabalhar isso diretamente com as pessoas. Por exemplo, quando elas falavam bastante, ou traziam múltiplas demandas, eu buscava acolher e sintetizar o seu relato, buscando negociar com elas o manejo do tempo de consulta e da escolha das demandas a serem trabalhadas naquele dia, utilizando a técnica da metacomunicação.

\section{Processos proximais com os usuários}

No campo da interação médica com os usuários, a formação em terapia relacional sistêmica provocou uma mudança na minha forma de lidar com as demandas clínicas. Utilizando o olhar sistêmico, constatei que muitos sintomas trazidos pelas pessoas eram respostas a interações que elas estabeleciam, mais diretamente com os seus familiares.

O cenário em que estava inserida era o de uma grande quantidade de atendimentos por dia com a oferta de intervenções amplas, que iam desde as consultas até a realização de procedimentos - pequenas cirurgias, lavagem de ouvido, entre outros. Além disso, devido à formação em terapia relacional sistêmica, reservava alguns horários na agenda para atendimentos familiares, geralmente no final do turno, com duração de 40 minutos a 1 hora.

A orientação dada aos usuários para organizar esses atendimentos era que, para conseguir intervir melhor nos sintomas, era necessário reunir toda a família. A adesão aos atendimentos era maior com aqueles usuários cujo vínculo já estava mais estabelecido. Poucos recusavam o convite de chamar a família. As vantagens de fazer esse tipo de atendimento na atenção primária consistem em ofertar a terapia de família em um local próximo à casa das pessoas e ajudá-las a ter acesso a uma modalidade de terapia, uma vez que algumas pessoas desconhecem esse tipo de atendimento ou têm uma visão equivocada sobre psicoterapia.

Mais detalhes dos processos proximais relacionados com os usuários serão apresentados a partir de recortes de situações clínicas acompanhadas.

\section{CASO ILUSTRADO 1 - A CRIANC̣A AGRESSIVA}

Pelo menos uma vez por mês, aparecia a demanda, trazida por pais ou por meio do Programa Saúde na Escola (PSE), de atendimento para crianças com comportamentos externalizantes - agressividade, hiperatividade, desobediência. Esses casos foram conduzidos utilizando a visão bioecológica do desenvolvimento infantil. Dessa forma, foi possível ampliar o foco para além dos atributos individuais de cada pessoa, como o temperamento da criança, por exemplo, e observar como situações relacionais e de contexto interferiam no comportamento da criança e na sua interação com o meio. Outra teoria que pode ser aplicada para esses casos é a teoria do apego. Crianças que desenvolvem um apego inseguro podem ter dificuldades de adaptação em relação às suas competências culturais. Quando existe muita intimidade da criança com o cuidador principal e pouca autonomia, um comportamento agressivo pode representar a forma que 
a criança encontrou para que a mãe responda às suas demandas ${ }^{\mathbf{1 2}}$.

Percebi que, em praticamente todos os casos acompanhados, houve a ausência da figura paterna na vida da criança, por vários motivos: separação dos pais e a guarda da criança estava com a mãe; ou o pai estava presente fisicamente, mas alheio às questões de criação dos filhos, seja por situações do trabalho ou por questões relacionadas à sua própria história pessoal. Por isso, uma intervenção sistêmica consistiu em trabalhar esses aspectos e a coparentalidade na família. Por meio do modelo bioecológico, realizei como intervenção o mapeamento dos mesossistemas dessas crianças. Procurei unir, por exemplo, a escola que a criança frequentava e a família, para elaborar estratégias conjuntas de manejo. Além disso, trabalhei a forma como o exossistema das crianças em relação aos pais - emprego do pai, por exemplo - interferia nesses processos proximais. Não foi possível intervir em questões relacionadas com o macrossistema, avaliando a questão da cultura dos pais, suas crenças e a influência do estilo de vida adotados na formação dessas crianças, mas isso pode ficar como uma sugestão de intervenção para outros momentos, em grupos de pais por exemplo.

Realizei abordagens relacionadas com os estilos parentais em alguns casos. Pode-se compreender os estilos parentais a partir de quatro estilos principais: o autoritário, no qual os pais são muito exigentes com a criança e demonstram pouco carinho por ela; o permissivo, em que a criança tem pouco limite e muito afeto; o negligente, em que o limite e afeto são poucos; e o estilo participativo, no qual há limite combinado com afeto e trocas entre pais e filhos, o que leva ao desenvolvimento da autonomia dos últimos ${ }^{13}$. Por exemplo, algumas crianças em que a queixa de comportamento externalizante era apenas dos pais, foi possível identificar um estilo autoritário de parentalidade, fazendo com que a criança sinalizasse por meio de sua forma de agir que precisava ter um pouco mais de liberdade e mais afeto. Os estilos negligente e permissivo também foram encontrados.
O trabalho realizado consistiu em ajudar esses pais a desenvolverem um estilo participativo.

\section{CASO ILUSTRADO 2 - ABORDAGEM DE SINTOMAS INDIFERENCIADOS}

Nos atendimentos, identifiquei muitos usuários com sintomas indiferenciados, alguns deles síndromes funcionais - fibromialgia, fadiga crônica, cefaleia. Às vezes, essas pessoas buscam atendimento com o objetivo de conseguir intervenções diagnósticas e terapêuticas, mesmo sem indicação e evidência científica para elas, até encontrarem uma explicação orgânica para a doença. Quando o médico de família utiliza a terapia sistêmica, esta se torna mais um instrumento para lidar com sintomas indiferenciados, que são muito comuns na atenção primária. Dessa forma, é possível fazer a prevenção quaternária, evitando que essas pessoas sejam submetidas a procedimentos médicos desnecessários.

É necessário aprender a não rotular essas pessoas como portadoras de transtornos psiquiátricos, como acontece em alguns serviços de saúde. Isso seria uma forma linear de lidar com esses sintomas. Após fazer a avaliação diagnóstica e tratamento para alívio sintomático, eu fazia o manejo longitudinal do problema ampliando a demanda, não intervindo apenas na queixa, conforme sugere Edith Tilmans ${ }^{\mathbf{1 4}}$. Entretanto, o dilema que vivenciei com alguns usuários consistiu no fato de que eles queriam apenas a resolução do sintoma, mas não queriam trabalhar questões emocionais, tampouco dificuldades relacionais, conforme está descrito na literatura ${ }^{14}$. Por isso, é importante avaliar bem com a pessoa quais serão as consequências, como ficaria a família se o sintoma fosse eliminado.

É necessário conhecer a reação dos membros da família quando o sintoma surge e qual o seu papel na dinâmica familiar. Por exemplo, acompanhei uma situação em que uma usuária desenvolveu dor torácica exatamente no momento em que a filha não quis morar com ela. Após afastar causas orgânicas 
que necessitassem medidas emergenciais infarto agudo do miocárdio por exemplo -, as intervenções consistiram em trabalhar questões de diferenciação entre mãe e filha e aspectos relacionados com o ciclo de vida familiar ${ }^{15,16}$. Outro fato importante observado foi a presença de vários membros da família com sintomas indiferenciados, por exemplo, fibromialgia. Um recurso interessante que poderia ser trabalhado nesses casos seria intervenções com a fratria, marcando atendimentos familiares com esses irmãos ${ }^{14}$.

Outro tipo de abordagem de sintomas indiferenciados que poderia ser utilizado seria a exploração destes, entendendo a sua função em nível emocional, comportamental e ideativo, conforme proposto por Peggy Papp 17. O nível emocional permite conhecer em quais momentos na vida da família o sintoma aparece. O nível comportamental possibilita conhecer a sequência de comportamentos da pessoa e dos outros membros da família diante do sintoma. Já o nível ideativo engloba as regras da família, mitos e crenças que podem perpetuar os sintomas.

A abordagem trazida pelas práticas narrativas, outro recurso advindo do construcionismo social e muito próximo às teorias sistêmicas, pode ser utilizada para fundamentar a atuação terapêutica no que se refere às crenças. Uma de suas práticas consiste em utilizar as conversas externalizantes. O problema ou o sintoma está tão presente na vida das pessoas que, muitas vezes, tudo gira em torno dele. Por meio das conversas externalizantes, é possível separar o problema da pessoa de sua própria identidade, saindo do discurso saturado do problema que a família traz e criando conversas de reautoria, para trazer novos significados e padrões às vidas dessas pessoas ${ }^{18}$.

\section{CASO ILUSTRADO 3 - MANEJO DE DOENÇAS CRÔNICAS NA FAMÍLIA}

As doenças crônicas são estressores verticais na vida familiar, devido ao aumento da longevidade e ao controle de várias doenças que anteriormente não tinham tratamento ${ }^{19}$. As intervenções sistêmicas foram utilizadas para aqueles casos em que a família apresentava dificuldade para adaptar-se às mudanças e, em outros, quando havia pouca adesão ao plano de tratamento. Utilizei o modelo bioecológico de Bronfenbrenner principalmente para analisar o mesossistema da pessoa, organizando as redes de apoio para o suporte nos momentos difíceis. Quanto aos processos proximais, trabalhei a interação da pessoa doente com seus familiares. Por exemplo, em um dos casos, foi possível perceber que uma senhora diabética não tomava as medicações, mesmo sem ter dificuldade cognitiva para lembrar-se de tomá-las e sabendo sobre a importância do tratamento. Isso a levava a ter episódios de hiperglicemia e a sentir-se mal, assim os filhos aproximavam-se e cuidavam dela - quando estava tudo bem com a sua saúde, os filhos se ausentavam.

A avaliação da dinâmica familiar é necessária porque, quando se mostra disfuncional, geralmente piora o curso da doença ou atrapalha na adesão ao tratamento. Além disso, é essencial conhecer a capacidade da família para tolerar situações que podem gerar grande estresse emocional, a resiliência familiar. É importante investigar como a família lidou com doenças anteriores, observar se há alguma diferença na forma de lidar com doenças graves e menos graves ${ }^{19}$. É importante observar se a doença trouxe mudanças nos relacionamentos. O genograma pode ajudar a demonstrar novas alianças, rompimentos, triangulações, a coesão familiar, entre outras relações, desenvolvendo intervenções a partir disso.

No processo de tempo, é preciso analisar o ciclo de vida familiar e individual para avaliar se existem repercussões multigeracionais ${ }^{19}$. As fases do desenvolvimento da família podem não acontecer, por exemplo, saída dos filhos de casa, ou pode atrapalhar na diferenciação desses indivíduos. Esses aspectos foram trabalhados em uma família cujo pai desenvolveu câncer. O filho adolescente ainda era tratado pelos pais como criança, os pais não conseguiram fazer as mudanças no relacionamento com ele, 
adaptando para a forma de relacionar-se com um adolescente, porque o foco da família estava direcionado para o problema de saúde do pai.

\section{Contexto}

O principal microssistema em que estava inserida era a Equipe de Saúde da Família, na unidade básica de saúde. As casas dos usuários que recebiam visitas domiciliares faziam parte de outros microssistemas. Essas visitas eram realizadas para aquelas pessoas com dificuldades de locomoção ou quando se precisava fazer busca ativa por falta de adesão ao acompanhamento. Além disso, em algumas visitas, realizava abordagens familiares. $O$ distrito sanitário era outro microssistema, uma vez que interagia com a unidade de saúde e comigo diretamente por meio de capacitações e suporte gerencial. Outros microssistemas foram a creche e a escola da comunidade, pelo fato de terem sido feitas algumas discussões de casos entre estes setores. Alguns profissionais da atenção secundária também eram microssistemas, devido à discussão de casos por meio do matriciamento. Dessa forma, foi possível perceber que o meu mesossistema era muito diversificado, como pode ser visto na figura 2 .

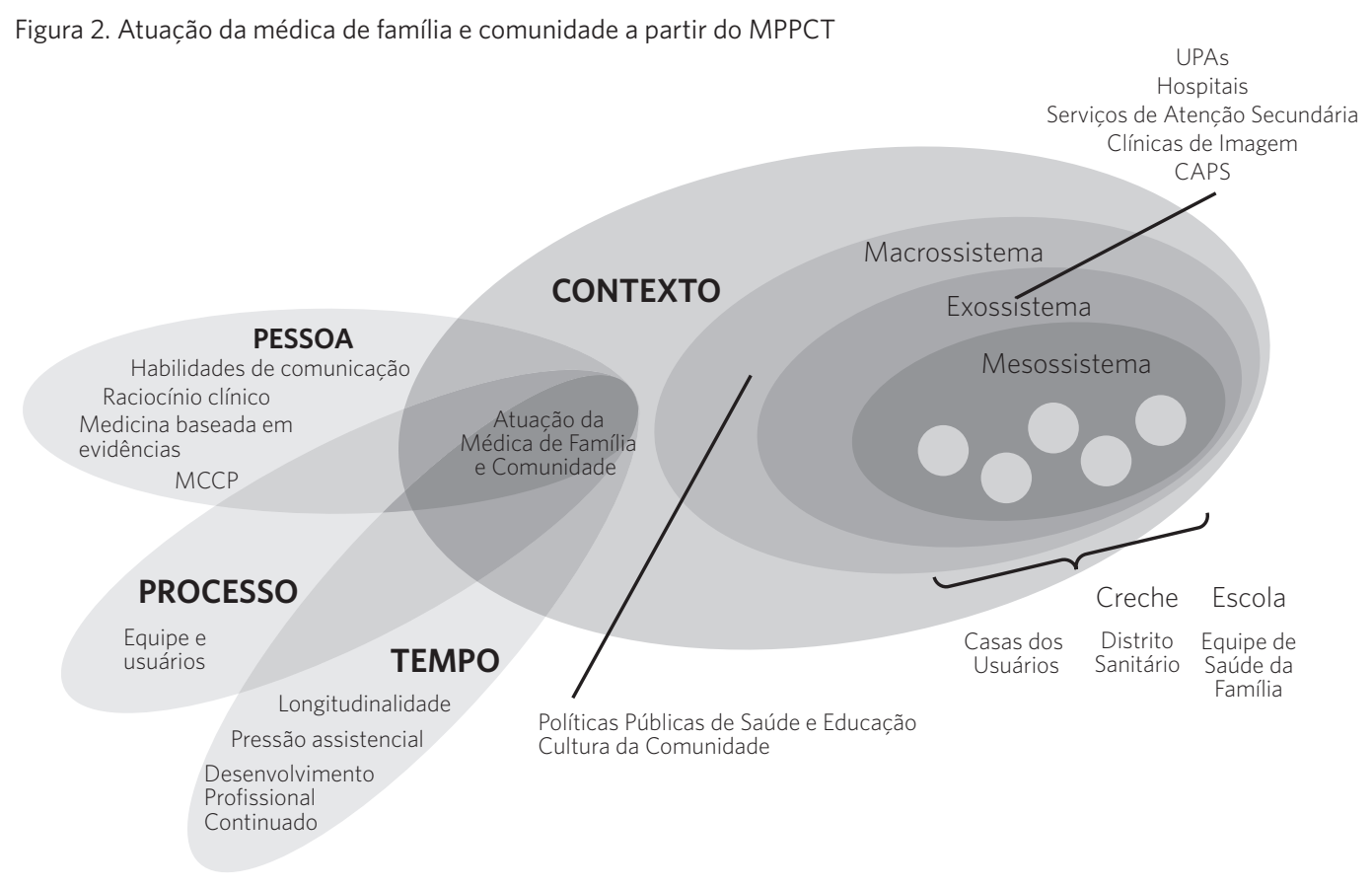

Fonte: Elaboração própria.

Os exossistemas constituíram nas interações que aconteciam entre os outros locais que os usuários frequentavam e que influenciavam indiretamente o meu trabalho. Esses locais habitualmente eram os serviços de atenção secundária, hospitais, Unidades de Pronto Atendimento (UPA) laboratórios, clínicas de imagem, Centros de Atenção Psicossocial (Caps) etc. Eu fazia a coordenação de todo o cuidado destinado aos usuários.

Compunham o macrossistema: a cultura em que a comunidade está inserida, a religião, aspectos políticos, econômicos. Há uma influência direta das políticas públicas de saúde e 
educação no processo de adoecer da comunidade, inclusive na identificação dos sintomas e na forma como os usuários buscavam a unidade de saúde. Em certos momentos, a unidade de saúde e os profissionais com quem as pessoas faziam vínculos eram as únicas redes de apoio com as quais alguns usuários contavam.

\section{Tempo}

O tempo consistiu em um dos fatores que me proporcionou a possibilidade de construir mais vínculo com a comunidade, ajudando na compreensão dos problemas e, consequentemente, aumentando a resolutividade, sendo estes pontos chave do atributo da longitudinalidade. Durante o período em que estive cursando a formação em terapia relacional sistêmica, consegui adquirir novas habilidades para o manejo dos casos, aperfeiçoando a forma de relacionar-me com os usuários. Essas mudanças foram agregadas ao processo de desenvolvimento profissional continuado que os médicos de família devem buscar.

Por outro lado, encontrei alguns obstáculos envolvendo questões globais sobre o tempo. Houve momentos em que uma grande demanda de atendimentos impossibilitava a existência de um horário completamente protegido para realizar as sessões de terapia com as famílias. Às vezes, organizava-me para fazer as sessões no final do turno, porém, quando havia grande demanda de outros usuários por atendimento, o tempo destinado para a sessão era reduzido. Outra dificuldade encontrada era colocar limites para os usuários, quando estes compareciam à sessão e solicitavam também um atendimento clínico. O que eu fazia era negociar com eles o que poderia ser feito no tempo destinado para a sessão. Se a população sob minha responsabilidade fosse menor, esse problema não seria tão prejudicial. Essa questão do tempo é um dos fatores que faz com que alguns médicos de família considerem que não é possível ser médico e terapeuta de família no mesmo cenário.

Analisando o meu trabalho a partir do fator tempo, no decorrer de meses após o acompanhamento de algumas famílias, aconteceram mudanças importantes: desaparecimento de sintomas que prejudicavam a família, por exemplo, nos casos das crianças com comportamento externalizante, melhora significativa de quadros de depressão e ansiedade, diferenciação e desenvolvimento de maior autonomia de alguns membros. Algumas famílias avaliavam que as sessões estavam trazendo mudanças na dinâmica familiar, com modificações do padrão de comunicação e nas relações entre os membros.

Outro aspecto desta dimensão do tempo refere-se às expectativas que a família possuía sobre o acompanhamento e às minhas expectativas. Havia espaço para a família trazer aquilo que ela gostaria de trabalhar no momento. Muitas vezes, o terapeuta observa muitos pontos que podem ser melhorados na família. Por exemplo, problemas no funcionamento familiar, de fronteiras, sintomas apresentados por algum dos membros. Entretanto, nem sempre a família deseja mudanças nos aspectos que o terapeuta identifica. Por isso, é imprescindível dar tempo à família, para que ela se adapte ao acompanhamento e para que seja possível avançar no processo terapêutico.

\section{Considerações finais}

Este estudo apresentou a dinâmica de trabalho de uma médica de família e comunidade e terapeuta de família demonstrando que é possível realizar esse trabalho a partir de uma perspectiva sistêmica. No trabalho cotidiano da profissional, foi possível perceber algumas teorias sistêmicas que embasaram as intervenções, desde o momento da identificação das demandas até o manejo terapêutico no cenário da atenção primária. $O$ trabalho da médica transitava entre os graus 4 e 5 dos níveis de envolvimento com a família, propostos por Doherty e Baird, citado por McWhinney e Freeman 4 .

Essa é uma possibilidade de atuação que traz consigo muitos desafios, o que faz com que 
sejam poucos os profissionais que acumulem essas duas funções ${ }^{4}$. Alguns argumentam que o processo de trabalho da atenção primária pode inviabilizar a realização da terapia, principalmente devido à falta de tempo e à sobrecarga de trabalho, sendo possível apenas realizar uma abordagem sistêmica. O trabalho da médica de família deste estudo demonstrou um pouco dessa dificuldade, apesar de a profissional ter desenvolvido estratégias para lidar com isso. Outra dificuldade consistiu na falta de um espaço físico apropriado, visto que o local onde foram realizados os atendimentos era um consultório pequeno que não estava adequado para receber uma família numerosa por exemplo.

Alguns profissionais podem sentir receio de situações embaraçosas que podem surgir nesse processo. Por exemplo, como o médico de família desenvolve um relacionamento com as pessoas antes mesmo de iniciar a terapia, é possível que ele conheça segredos que os indivíduos não querem que sejam abordados com a família. Isso pode propiciar o desenvolvimento de alianças, sendo difícil manter a imparcialidade. Nesses casos, uma possibilidade consiste em encaminhar a família para outro terapeuta, para evitar o risco de agir de forma semelhante à família, fenômeno conhecido como isomorfismo. Portanto, o médico necessita refletir sobre os limites de sua atuação.

Por outro lado, o médico de família que também é terapeuta pode estar em uma posição privilegiada. No cenário da atenção primária, quando o atendimento é realizado com populações vulneráveis, a terapia de família torna-se mais acessível para aquelas pessoas que não possuem condição financeira para investir em uma terapia de família fora desse contexto. Os gestores poderiam dar um apoio para iniciativas como essa, por aumentar a resolutividade da atenção primária e devido ao fato de os psicólogos dos Núcleos de Apoio à Saúde da Família (Nasf) não conseguirem dar conta da demanda em virtude da sobrecarga de trabalho, em múltiplos centros de saúde. Outra proposta seria criar ambulatórios de terapia de família, para ter locais onde encaminhar os casos, e promover a realização de grupos - por exemplo: grupos de pais e multifamílias.

Ao estudar o trabalho do médico de família sob a perspectiva do modelo bioecológico do desenvolvimento humano, foi possível perceber o quanto é uma atuação complexa, com múltiplas interações. Quando um médico de família também é terapeuta, ele possui à sua disposição ferramentas e estratégias que ampliam a sua resolutividade, oferecendo um cuidado diferenciado para os indivíduos e suas famílias.

\section{Colaboradores}

Santos KPS (0000-0001-8923-2569)* contribuiu para concepção, planejamento, análise e interpretação dos dados do trabalho, elaboração do rascunho do conteúdo e participação na aprovação da versão final do manuscrito. Böing E (0000-0002-1242-9950)* contribuiu para orientação, concepção e delineamento do estudo, para a análise/interpretação dos dados do trabalho; revisão crítica de conteúdo intelectual; aprovação final da versão a ser publicada; concordância em ser responsável por todos os aspectos do trabalho, no sentido de garantir que as questões relacionadas à exatidão ou à integridade de qualquer parte da obra sejam devidamente investigadas e resolvidas. $\mathrm{O}$ artigo é derivado do Trabalho de Conclusão do Curso de Especialização em Terapia Relacional Sistêmica do Familiare Instituto Sistêmico, Florianópolis (SC). 


\section{Referências}

1. Starfield B. Atenção primária: equilíbrio entre necessidades de saúde, serviços e tecnologia. Brasília, DF: Unesco, Ministério da Saúde; 2002.

2. Gervas J, Fernández MP. Organização da Atenção Primária à Saúde em outros países. In: Gusso G, Lopes JMC, organizadores. Tratado de Medicina de Família e Comunidade: princípios, formação e prática. Porto Alegre: Artmed; 2012. p. 42-51.

3. Brasil. Ministério da Saúde. Portaria no 2436 , de 21 de setembro de 2017. Aprova a Política Nacional de Atenção Básica, estabelecendo a revisão de diretrizes para a organização da Atenção Básica no âmbito do Sistema Único de Saúde (SUS). Diário Oficial da União. 22 Set 2017.

4. McWhinney IR, Freeman T. Manual de medicina de família e comunidade. 3. ed. Porto Alegre: Artmed; 2010 .

5. Boing E, Crepaldi MA. Reflexões epistemológicas sobre o SUS e atuação do psicólogo. Psicol., ciênc. prof. [internet]. 2014 [acesso 2017 nov 26]; 34(3):745-760. Disponível em: http://www.scielo. br/pdf/pcp/v34n3/1982-3703-pcp-34-03-0745.pdf.

6. Junior NL, organizador. Currículo Baseado em Competências para Medicina de Família e Comunidade [internet]. [acesso 2017 set 7]. Disponível em: http://www.sbmfc.org.br/media/Curricu10\%20Baseado\%20em\%20Competencias(1).pdf.

7. Honzak R, Seifert B. Family Therapy skills for medical practitioners. The World Book of Family Medicine [internet]. Poljanski Nasip: Wonka, European Edition; 2015 [acesso 2017 jul 7]. Disponível em: http://www.woncaeurope.org/sites/default/ files/099\%20-\%20Family\%20Therapy\%20Skills. pdf.

8. Magalhães C, Nunes MAS. Terapia familiar em cuidados primários de saúde. Rev. Port. Med. Ge- ral e Familiar [internet]. 2001 [acesso 2017 jul 7]; 17(2):151-158. Disponível em: www.rpmgf.pt/ojs/ index.php/rpmgf/article/download/9832/9570.

9. Polonia AC, Dessen MA, Silva NPL. O modelo bioecológico de Bronfenbrenner: contribuições para o desenvolvimento humano. In: Dessen MA, Junior ALC, organizadores. A ciência do desenvolvimento humano: tendências atuais e perspectivas futuras. Porto Alegre: Artmed; 2005. p. 71-89.

10. Bronfenbrenner U. Bioecologia do desenvolvimento humano: tornando os seres humanos mais humanos. Porto Alegre: Artmed; 2012.

11. Satir V. Terapia de grupo familiar. Rio de Janeiro: Francisco Alves; 1988.

12. Pontes FAR, Silva SSC, Garotti M, et al. Teoria do apego: elementos para uma concepção sistêmica da vinculação humana. Aletheia [internet]. 2007 [acesso 2017 out 22]; 26:67-79. Disponível em: http://pepsic.bvsalud.org/pdf/aletheia/n26/ n26a07.pdf.

13. Weber L. Eduque com carinho. Curitiba: Juruá; 2014.

14. Tilmans-Ostyn E. A procura do terapeuta: da queixa à demanda. In: Tilmans-Ostyn E, Meynckens-Fourez M, organizadores. Os recursos da fratria. Belo Horizonte: Artesã; 2000. p. 57-72.

15. Bowen M. De la familia al individuo: la diferenciación del sí mismo en el sistema familiar. Barcelona: Ediciones Paidós; 1979.

16. McGoldrick M, Shibusawa T. O ciclo vital familiar. In: Walsh F. Processos normativos da família: diversidade e complexidade. Porto Alegre: Artmed; 2016. p. 375-398.

17. Papp P. O processo de mudança: uma abordagem 
prática à terapia sistêmica de família. Porto Alegre: Artes Médicas; 1992.

18. White M. Maps of narrative practice. New York: Norton; 2007.

19. Rolland JS. Enfrentando os desafios familiares em doenças graves e incapacitantes. In: Walsh F. Pro- cessos normativos da família: diversidade e com-

plexidade. Porto Alegre: Artmed; 2016. p. 373-392.

Recebido em 15/07/2018

Aprovado em 17/02/2019

Conflito de interesses: inexistente

Suporte financeiro: não houve 